ISSN: $2317-8957$

Volume 5, Number 1, Jun. 2017

\title{
REFLEXÕES SOBRE A EDUCAÇÃO AMBIENTAL CRÍTICA EM UM GRUPO DE PESQUISA: UM ESTUDO DE CASO DO GEASUR
}

\author{
MARCELO ARANDA STORTTI ${ }^{1}$, CELSO SANCHEZ PEREIRA ${ }^{1}$
}

${ }^{1}$ Programa de Pós-graduação em Educação da Universidade Federal do Estado do Rio de Janeiro (UNIRIO)

\section{RESUMO}

Neste trabalho admoestamos refletir sobre as pesquisas e a práxis de educação ambiental realizadas no âmbito do Grupo de Estudos de Educação Ambiental Desde El Sur (GEASur) da Universidade Federal do Estado do Rio de Janeiro (UNIRIO). Neste sentido, buscamos conhecer e refletir a educação ambiental produzida nesse grupo de pesquisa na perspectiva do sul global, bem como, a contextualização necessária às complexas realidades dessa região. Para o GEASUR, esta abordagem pedagógica parte de premissas Freirianas e do campo dos estudos decoloniais críticos. A partir desse referencial teórico-metodológico, apresentamos estudos de casos sobre a educação ambiental e as pedagogias de resistência dos grupos em luta contra as petroleiras na Argentina e no Brasil, mais especificamente no caso da Baía da Guanabara (RJ). A partir das analises das pesquisas anteriores, observa-se que essa aproximação teórica pode trazer contribuições para a perspectiva da pesquisa e da práxi em educação ambiental crítica sobretudo ao reconhecer as educações ambientais e as práxis pedagógicas constitutivas dos movimentos sociais anteriores que vão além dos processos de educação popular corriqueiramente observados. Esses movimentos se reinventam e criam novas estratégias a todo instante, logo apresentam potencial criador e criativo que pode ajudar a refletir a educação ambiental de uma forma profundamente estruturante em todos os seus espaços e formas de atuação.

Palavras-chave: educação ambiental, grupo de pesquisa, movimentos sociais.

\begin{abstract}
In this work, we admonish to reflect on the research and practice of environmental education carried out within the framework of the Group of Studies on Environmental Education Desde El Sur (GEASur) of the Universidade Federal do Estado do Rio de Janeiro (UNIRIO). In this sense, we seek to know and reflect the environmental education produced in this research group from the perspective of the global south, as well as the contextualisation necessary to the complex realities of this region. For GEASUR, this pedagogical approach starts from Freirianas premises and from the field of critical decolonia studies. Based on this theoretical-methodological framework, we present case studies on environmental education and resistance pedagogies of groups fighting against oil companies in Argentina and Brazil, more specifically in the case of Guanabara Bay (RJ). From the analysis of the previous research, it can be observed that this theoretical approach can bring contributions to the perspective of research and praxis in critical environmental education, especially when recognizing the environmental educations and pedagogical practices constitutive of previous social movements that go beyond the processes of popular education commonly observed. These movements reinvent themselves and create new strategies at all times, thus presenting creative and creative potential that can help to reflect environmental education in a deeply structuring way in all its spaces and ways of acting
\end{abstract}

Keywords: Environmental education, research group, social movements

\section{INTRODUÇÃO}

O objetivo desse artigo é refletir sobre as pesquisas e a práxis de educação ambiental realizadas no âmbito do Grupo de Estudos de Educação Ambiental Desde El Sur (GEASur) da Universidade Fede- ral do Estado do Rio de Janeiro (UNIRIO). $\mathrm{O}$ intuito desse grupo é pensar e conhecer a educação ambiental produzida na perspectiva do sul global e ao mesmo tempo realizar pesquisas que nos auxiliem a encontrar a contextualização necessária às complexas realidades que constituem a 
região sul americana em especial, Para Tal, será apresentado a perceptiva do grupo e em seguida apresentaremos um exemplo de uma investigação que dialoga com a perspectiva que o grupo vem adotando para exemplificar a operacionalidade dos recortes teóricos e conceituais do grupo.

O GEASur, nasce em junho de 2012, estando cadastrado no diretório de Grupos de Pesquisa do Conselho Nacional de Pesquisa (CNPQ) e vinculado ao Programa de Pós-graduação Mestrado e Doutorado em Educação (PPGEdu) da UNIRIO. Link

Esse grupo, reúne, servidores e servidoras técnico-administrativos, professores, estudantes de graduação e do programa de pósgraduação da UNIRIO, bem como, estudantes de graduação e pós graduação de outras universidades, professores de escolas públicas e privadas e militantes de diferentes movimentos sociais.

Essa adjetivação da educação ambiental em língua espanhola "Desde El Sur", foi propositalmente proposta para enfatizar a localização, mais que geográfica, epistemológica, afinada com a perspectiva latino-americana. Assim, nos interessa uma geoepistemologia que permita reconhecer, a partir dos territórios e da terra, as epistemologias emergentes de grupos em luta em defesa da vida e pelos distintos modos de produção da vida e do viver. Desta forma, o ponto de partida é o reconhecimento da preexistência de uma educação ambiental praticada e pensada a partir das realidades da região por parte dos movimentos sociais, grupos indígenas, povos do campo, comunidades quilombolas, comunidades afroameríndias, favelas, movimentos das periferias urbanas entre outros grupos que produzem uma contra hegemônica pelo seu modo de produção das suas próprias existências. Tal aspecto, nos remete a necessidade de ampliação da atenção e contextualização às demandas destes movimentos por justiça socioambiental, bem como o aporte do pensamento latino-americano em ecologia política e educação popular.

Esta abordagem pedagógica parte da pre missa Freiriana que educar e de educar-se é um ato político, e que "não ha saberes mais ou menos mais saberes diferentes" (FREIRE,1987, p.68).

Por essa linha de reflexões nos identificamos com o campo dos estudos decoloniais críticos e encontramos em autores como Henrique Dussel, Arturo Escobar, Catherine Walsh, Santiago Arboleda e Franz Fannon, elementos para debater a educação ambiental em uma perspectiva Decolonial Crítica, entendendo o estudo da questão Colonial por um vies critico, reconhecendo a persistência do projeto colonial no programa capitalista dependente destinado a América latina. Por isso demarcamos o debate a partir da perspectiva da decolonialidade crítica e não da pós-colonialidade.

O grupo se propõe atuar no ensino, pesquisa, extensão e na militância, fazendo a interface da educação ambiental em sua vertente crítica, com os movimentos sociais urbanos, campesinos, afrodescendentes, indígenas, justiça ambiental e ambientalista, entendendo o engajamento nos movimentos como parte do processo formativo de pesquisadores e participantes do GEASUR.

\section{REFERENCIAL TEÓRICO-METODOLÓGI-} $\mathrm{CO}$

O grupo defende que o a leitura e decupagem das práticas pedagógicas realizadas por esses grupos contra hegemônicos pode propiciar embasamento teórico e fundamentar um dialogo com a base social e os movimentos que a constituem.

Desta forma, crê-se que pode ser esta uma forma de encontrar a desejada contextualização às demandas da realidade socioambiental latino-americana. Portanto, busca-se identificar os possíveis diálogos que emergem das insurgências e demandas populares e dos movimentos sociais em torno da problemática socioambiental, a partir dos referenciais de estudos acerca da descolonialidade e da interculturalidade no contexto regional latino-americano.

Na perspectiva da decolonialidade, cabe ressaltar que Mignolo (2007) a entende como 
uma das três faces da Modernidade. Para este autor, a Modernidade se expressa de três maneiras: (1) o mito salvacionista, que compreende a ideia de que o progresso e o desenvolvimento solucionarão todos os problemas e "salvarão os selvagens" através da imposição de uma civilidade; (2) a colonialidade, que é representada pela herança colonial gerada a partir dos processos de colonização, no qual o pensamento colonial consiste em um pensamento anti-dialógico e, portanto, opressor; (3) a decolonialidade que surge como energia de resistência, ou seja, atos de rebeldia e enfrentamento contra o pensamento dominante.

Dessa forma, argumentamos que existe a possibilidade de aproximação entre os campos da decolonialidade e da EA Crítica, sobretudo no sentido de não esvaziar a problematização da discussão decolonial em função de um distanciamento das categorias centrais do campo crítico. Acredita-se que essa discussão pode vir a apontar caminhos para a superação da linguagem hegemônica na EA que ainda é permeada por propostas conservadoras e pragmáticas que reforçam uma perspectiva de ocultamento das contradições e dos conflitos socioambientais. Além disso, a possibilidade de articular o campo da EA com outros campos do pensamento social, como a decolonialidade, pode contribuir para fortalecer a EA e seu papel nas lutas por justiça socioambiental.

Este estudo, foi organizado utilizando o paradigma da teoria crítica e como parâmetros de análise, o conceito que defendem que certas atividades afetam a estabilidade de outras formas de viver mediados por impactos causados no ambiente e nas pessoas gerando conflitos ambientais (ACSELRAD, 2004). E identificam a existência de um projeto hegemônico do capital, orientado pelo discurso do desenvolvimento promovendo uma desconcentração e redistribuição do controle do capital industrial, constituindo no capitalismo colonial-moderno e a sua resistência a Decolonialidade (QUIJANO, 2010). Além disso, dialogamos com a noção de Educação Ambiental em uma perspectiva crítico-transformadora (LOUREIRO, 2004).

\section{PRIMEIROS PASSOS DA IMERSÃO NA AMÉRICA LATINA}

Para tal, o grupo iniciou a sua ação a partir do desenvolvendo de uma escuta sensível (MONTEIRO, SANCHEZ e GUIMARAES, EPEA ) desenvolvendo o projeto "Diálogos desde el Sur" no qual se propõe debates sobre temas comuns e integradores às realidades socioambientais de nossa região.

Em 2013 o "Diálogos desde el Sur" Brasil-Peru discutiu o racismo na América Latina, quando se apresentou o filme "Choleando" que discute a tematica racial no Perú, como uma mesa de debate formada por intelectuais negros brasileiros, e imigrantes peruanos.

Em 2014 foi a vez do "diálogos” Brasil Cuba debateu a educação ambiental popular em Cuba com a preseça do pesquisador Jesus Jorge Perez Garcia da Universidade Pedagógica Rafael Mendivem com a qual a UNIRIO realizou convenio formal de cooperação.

Em 2014 discutiu-se a relação Brasil -Colômbia, através do evento "Colombia al Derecho y al Reves" que trouxe intelectuais, movimentos sociais e lideranças políticas para o Rio Em 2015 na Universidade Rafael Mendive, realizou-se o encontro "Diálogos desde el Sur".

Em 2016 O grupo realiza em Dezembro um novo "diálogos" com vários coletivos de imigrantes latinoamericanos e africanos no Rio de Janeiro. Na ocasião pode-se discutir a questão colombiana e seus conflitos numa perspectiva socioambiental.

Paralelamente aos diálogos, foi-se construindo um grupo de estudos que fomentaram o desenvolvimento de trabalhos de conclusão de curso, dissertações e Teses (www.geasur. wordpress.com).

A diversidade do grupo enriquece trocas de experiências, de conhecimentos e de vivências no campo da educação ambiental crítica. As pesquisas atuam no campo da educação ambiental comunitária, da ecologia política, da justiça ambiental e territorialidade, da ecologia de saberes, educação ambiental à distância e processos de formação de educadores ambien- 
tais a partir de saberes indígenas.

\section{METODOLOGIA DE TRABALHO}

O GEASur prioriza uma metodologia de trabalho coletivo, onde as reuniões semanais são espaços de escrita, orientação, aulas e leituras em grupo, acreditando que este espaço traga aprendizagens com o potencial de proporcionar trocas de saberes e de conhecimentos de uma forma diferenciada do modelo de produção ou de estudo individual. Segundo o próprio Paulo Freire, uma de nossas referências de base, no livro a Pedagogia do Oprimido (1981, p.23), "ninguém educa ninguém, ninguém se educa sozinho. As pessoas se educam entre si". O grupo realiza imersões para vivenciar e aprofundar alguns temas. Além disso, organiza diversos eventos científicos, tais como "Diálogos Desde El Sur"; Fórum de Educação Ambiental Crítica, o Encontro de Educação Ambiental em Contextos Escolares, o Encontro de Pesquisa em Educação Ambiental (EPEA) e participa das comissões científicas (avaliação de trabalhos) do Seminário de Justiça ambiental, Racismo e Educação (SEMIJAIRE) e Encontro Nacional de Ensino e Pesquisa em Biologia (ENEBIO) entre outros.

\section{RELATO DE UMA PESQUISA COM ABOR- DAGEM "DESDE EL SUR".}

A partir das reflexões anteriores, apresentamos uma pesquisa realizada sobre a educação ambiental e as pedagogias de resistência dos grupos em luta contra as petroleiras na Argentina organizadas em torno do Observatorio Petrolero Sur (OPSur ) e na Baia da Guanabara organizados pelo Fórum dos Atingidos pelo Industria do Petróleo e Petroquímica da Baia da Guanabara (FAPP-BG).

A expansão da fronteira petroleira tem fomentado o aumento dos crimes ambientais e consequentemente dos conflitos e injustiças ambientais na América Latina. Sobre essa questão podemos destacar os processos das lutas sociais ocorrido na Argentina, após o aumento da exploração e refinamento do petróleo em territóri- os de populações originárias e pobres, propiciando a promoção de diferentes ações coletivas que podem estar relacionadas a ideias pedagógicas e de educação ambiental pouco conhecidas por esse campo. Esse movimento surgiu em 2008 e se localiza na cidade de Buenos Aires e Neuquen e tem como principal objetivo orientar a produção e consumo de energia de forma justa, democrática, saudável e sustentável. Esse grupo articula parcerias com diferentes organizações sociais, como ONGs, movimentos de bairro ou direitos civis, comunidades indígenas e a rede Oilwatch. Essas parcerias resultaram em 2002 na realização de um mapeamento coletivo dos conflitos socioambientais relacionados a cadeia produtiva do petróleo. A partir disso, esse grupo busca instituir uma outra matriz produtiva e energética no âmbito de um quadro de justiça ambiental e social, incentivando e organizando ações para combater a concentração de poder e sonhando com uma mudança social e a construção de novas utopias. Dentro do escopo dos materiais didáticos apresentados no site do OPSur observamos que está disponível desde livros eletrônicos que tratam do tema do petróleo, do "Fracking", energia eólica, justiça ambiental, energia solar para escolas e materiais didáticos em educação ambiental do Greenpeace e do Centro Nacional de Educação Ambiental, ambos, da Espanha. Esse movimento produziu um documentário em quatro capítulos denominada "Território Crudo". O primeiro capitulo aborda o conflito ambiental entre a industria petrolífera e uma área de proteção ambiental da argentina, o segundo apresenta o conflito entre a exploração de petróleo e o modo de vida da comunidade indígena Mapuche, o terceiro os problemas ambientais e de saúde de um vizinho indesejado (as empresas). E o último retrata os conflitos entre produtores de frutas, moradores de chácaras e as empresas. Além disso, esse grupo também usa como estratégia as mobilizações de vizinhos para protestar contra os problemas ambientais e outros temas. (STORTTI, SANCHEZ. 2016).

Já na Baia da Guanabara, o que se observa é a ampliação das estruturas para a cadeia produtiva do petróleo, 
como com sequencia da ampliação da demanda global por comoditeis o que fez com que a principal empresa petroleira do Pais, viasse a disputar territórios com populações residentes criando zonas de sacrificios e elevando esse contingente populacional a condição de oprimidos ambientais e populações de sacrifícios.

Por zonas de sacrifícios compreendemos definição de Ascerald (2004), segundo Rios (2016) as populações presentes nessas zonas de sacrifícios, podem ser consideradas populações de sacrificios pois saõ parcelas da população sobre as quais recaem de forma desigual danos ambientais tornando-as vulneráveis socioambientais. Tais contingentes populacionais por sua vez sofrem mais diretamente os impactos ambientais bem como, os processos de chantagem ambiental e cooptação das empresas e dos governos aliados a esses projetos desenvolvimentistas hegemônicos que interferem no território impondo processos de reorganização restruturação e redistribuição de danos ambientais.

Além disso, conceitos como território, lugar e paisagem que são do campo da geografia Política passam a ser importantes para entendermos que meio ambiente não é só um dado, uma coleção de objetos da natureza, bem como, não se trata de um "recurso natural". Logo podemos pensar que a análise de Fannon (2001) sobre os "Condenados da Terra", mesmo não se tratando especificamente dos sujeitos históricos relacionados as lutas ambientais, pode ser relacionada a esse grupo, Essa análise, se aproxima muito do que Freire (1989) chamava de Pedagogia do Oprimido, logo podemos afirmar que esses sujeitos podem ser identificados como "Condenados/Oprimidos Ambientais", isto é, a dimensão da opressão ambiental se revelando nesse cenário de lutas socioambientais. E como a educação está relacionada a essa questão?

Nestes dois casos vemos operar um mesmo mecanismo de opressão ao qual podemnos identificar o componente ambiental como a principal gatilho produtor de opressão, a isso temos denominado de oprimidos ambientais, tendo nos autores citados anteriormente as referências para pensar uma educação ambiental que que vai construir processos de superação das condições de opressão (UCHÔA, CASTRO, SANCHEZ, 2016).

Dessa forma nos interessa nesse trabalho observar as pedagogias dos movimentos de resistência ou seja partimos do pressuposto que essas experiências produzem pedagogias e essas são fundamentais para a fundamentação da luta socioambiental.

Além disso, podemos observar que existe um dialogo entre o conceito de Decolonialidade e as ações coletivas desses grupos sociais em resistência, isto é, pode-se perceber que destes grupos parti uma reflexão radical e a construção de um processo de superação das mais distintas formas de opressão perpetradas contra as classes e os grupos subalternos pelo conjunto de agentes, relações e mecanismos de controle, discriminação e negação da modernidade/colonialidade.

Podemos supor que o dialogo que se instaura a partir da ecologia política e do campo da geografia política, faz-se através do entendimento das condições materiais objetivas nas quais se dão as territorialidades das populações em condições de vulnerabilidade socioambiental, bem como, a ideia de "raça", como ferramenta de classificação, controle social e o desenvolvimento do capitalismo (WALSH, 2009).

Para Carvalho (2000) a inserção orgânica na luta pelos bens comuns promove uma dimensão pedagógica através do efetivo embate entre projetos políticos, questões culturais e sociais diferentes. Bogado (2011) reforça essa ideia afirmando que uma das características de um movimento social está relacionada aos processos de ensino-aprendizagem que se desenvolvem no interior das suas ações coletivas. Segundo essa autora, esse potencial educativo, tem relação direta aos novos sujeitos participantes desses movimentos, com novas racionalidades, propiciando novas oportunidades de viver e reviver novas experiências existências, questionando as normas e regras da sociedade capitalista, que na nossa concepção não estão amarradas e direcionadas na pedagogia da hegemonia/colonial, como citamos, tornando-se 
uma corrente contra-hegemônica na transformação social que um determinado coletivo deseja alcançar.

Como podemos observar anteriormente Fanon (2001) e Freire (1989) contribuem com uma proposta que relaciona o político e o pedagógico com o objetivo de oferecer um entendimento real "em favor das lutas de descolonização, libertação e humanização" tal como sintetiza WALSH (2013, p. 42).

Essa autora ainda explica que as pedagogias decoloniais estão vinculadas a processos "históricos-socio-políticos", relacionadas às lutas das pessoas vivenciadas em um mundo colonial, representando ações e metodologias que fortalecem a construção das resistências, insurgências epistêmicas, interferindo nos campos do ser, saber e poder (WALSH, 2009; 2013).

Diante desses pensamentos podemos se perguntar que educação ambiental ocorre nesses grupos socais? Aquela que prega consensos? Ou a Colonialidade do Poder (QUIJANO, 2010) Cooperação para o modelo hegemônico de Desenvolvimento Sustentável? Ou uma educação ambiental crítica/decolonial? Aquela que permite que esses sujeitos percebam a sua dimensão de condenados/oprimidos e de sujeitos historicamente construído, a ponto de perceber a sua inserção territorial, sua construção subjetiva e essa tomada de consciência territorial a cerca da sua vulnerabilidade e da sua condição de condenado/oprimido relacionada a esse processo de educação que leva a essa tomada de consciência da realidade.

\section{CONSIDERAÇÕES FINAIS}

Percebemos estar diante de um grande desafio, refletir sobre a possibilidade de uma educação ambiental critica/decolonial, que emerge de grupos subalternizados que organizados em torno das lutas em defesa da vida e os modos de produção da vida e existência constituem processos pedagógicos outros aos quais a universidade sobre tudo os grupos de pesquisas interessados em educação ambiental precisam estar atentos, e para tal defende-se a escuta sensível (SÁNCHEZ ET AL, 2010).
Nesse sentido, revindicamos a importância de decolonizar o pensamento ambiental, para que o debate possa ser visto para além do projeto hegemônico da Década do Desenvolvimento Sustentável. Este trabalho portanto, procurou apresentar as perspectivas de pesquisa do GEASUR e realizar inter-relações entre os os diferentes campos e construções teóricas em formações diferentes, tanto por um lado, os estudos de decolonialidade na perspectiva Latino americana e por outro a educação ambiental critica e da Ecologia Política.

Compreende-se que essa aproximação teórica pode trazer contribuições para a perspectiva da pesquisa e da práxi em educação ambiental crítica sobretudo ao reconhecer as educações ambientais e as práxis pedagógicas constitutivas dos próprios movimentos sociais que vão além dos processos de educação popular corriqueiramente observados. O que podemos ver é que tais movimentos se reinventam e criam novas estratégias a todo instante. O potencial criador e criativo de tais grupos pode ajudar a oxigenar a educação ambiental de uma forma profundamente estruturante em todos os seus espaços e formas de atuação.

\section{REFERÊNCIAS BIBLIOGRAFICAS}

ACSELRAD, Henry (Org.). Conflitos social e meio ambiente. Rio de Janeiro: Relume Dumará: FASE, 2004.

BOGADO, Adriana. "A luta também te ensina": Processos de Ensino-aprendizagem no Marco de Movimentos Sociais Argentinos. AURORA. Ano V, número 8, agosto. 2008.

FANON, Franz. Os Condenados da Terra. Juiz de Fora: Ed. UFJF, 2005.

FREIRE, Paulo. Pedagogia do Oprimido. Rio de Janeiro: Paz e Terra.1987.

LOUREIRO, Carlos Frederico Bernardo. Trajetória e fundamentos da educação ambiental. 
São Paulo, Cortez, 2004.

QUIJANO, Anibal. "Bien Vivir": entre el "Desarrollo" y la Des/Colonialidad del Poder. Boletim OXFAM, mayo. 2010. Disponível em: www.quijano.com.br. Acesso em: 11/01/16.

SANCHEZ, C.; MONTEIRO, B.; MONTEIRO, R. Na Trilha das Pedras: Algumas considerações sobre as metodologias de Educação Ambiental e o Processo de Escuta. Rev. Eletrônica Mest. Educ. Ambient., v. 24, 2010. Disponível em: https://www.seer.furg.br/remea/article/ viewFile/3910/2336. Acesso em: 10/02/16.

SVAMPA, Maristella. Consenso de los Commodities, Giro Ecoterritorial y Pensamiento crítico en América Latina. Revista del Observatorio Social de América Latina. año XIII n 32, novembro. 2012. Disponível em: http://biblioteca.clacso.edu.ar/clacso/ osal/20120927103642/ OSAL32.pdf . Acesso em: 01/11/15.

STORTTI, Marcelo, SANCHEZ, Celso. A geopolítica das lutas e conflitos socioambientais na América Latina: perspectivas para a educação ambiental contextualizada a justiça ambiental. V Seminário de Justiça ambiental, Igualdade Racial e Educação. 2015. Disponível em: www. semijaire.com.br. Acesso em: 21/12/15.

WALSH, Catherine. Interculturalidade Critica e Pedagogia Decolonial: In-surgir, Re-existir e Re-viver. In: CANDAU, Vera Maria (org.). Educação Intercultural na America Latina: entre Concepções, tensões e propostas. Editora 7 letras. 2009. WALSH, Catherine. Pedagogías decoloniales: prácticas insurgentes de resistir, (re)existir y (re)vivir. Quito, Ecuador: Ediciones Abya-Yala, 2013.

UCHÔA, R.; CASTRO, L.; SANCHEZ, C.. Por uma educação ambiental contra-hegemônica: a construção do conceito de oprimido ambiental em paulo freire a partir da análise crítica da década da educação para o desenvolvimento sustentável (DEDS). III Fórum de Educ. Ambi- ental Crítica. 2016. Disponível em: https://pt-br. facebook.com/events/562800900576805. Acesso em: 02/12/16. 